\title{
Gastrointestinal Malignancies: An Eight Years Experience
}

\author{
Binita Goyal,' Mamata Sedhain,' Pratigya Subedi, Suman Rai' \\ 'Department of Pathology, College of Medical Sciences, Bharatpur, Chitwan, Nepal.
}

\begin{abstract}
Introduction

Gastrointestinal malignancy constitutes a significant cancer burden in terms of mortality. They are most often detected late due to hidden location and lack of symptoms. This study was undertaken with an aim to see age and site distribution, histopathological spectrum, histologic grade and pathologic stage at presentation and to find correlation between histologic grade and pathologic stage at presentation.
\end{abstract}

\section{Methods}

This retrospective chart review was carried on 161 cases of GI malignancies received in Department of Pathology of College of Medical Sciences and Teaching Hospital during a time period of 8 years from January 2012 to December 2019.

\section{Results}

Age of the patients ranged from 16 to 93 years with a mean \pm SD of $57.3 \pm 16.3$ years with maximum $36(22.4 \%)$ cases in 51-60 years age group and a male female ratio of 1.4:1. 29 (18.0\%) cases were seen at or below 40 years of age. Stomach was the most common site involved in 69 (42.9\%) cases. Majority, 136 (84.5\%) cases were adenocarcinoma. Majority, 48 (35.3\%) cases of adenocarcinoma were Grade 2. Most 31 (45.0\%) cases were Stage III at presentation. There was no statistical significant association between histologic grade and pathologic stage $(p=0.073)$.

\section{Conclusions}

GI malignancy constitutes a significant cancer burden. Younger individuals are also considerably affected denoting a need of high degree of suspicion. Stomach was the most common site involved. Adenocarcinoma was the most common histological type. There was no association between histologic grade and pathologic stage at presentation $(\mathrm{p}>0.05)$.

Keywords: Colorectal; gastrointestinal; GI malignancy.

Correspondence: Dr. Binita Goyal, Department of Pathology, College of Medical Sciences, Bharatpur, Chitwan, Nepal. Email:binitagoyal@yahoo.com. Phone: +977-9860167741. 


\section{INTRODUCTION}

The gastrointestinal (GI) tract is a hollow tube that extends from oral cavity to anus and consists of anatomically distinct segments including esophagus, stomach, small intestine, colon, rectum and anus. Each of these segments has unique, complementary and highly integrated functions which together serve intake, digestion and absorption of ingested food particles and disposal of waste products. $^{1}$

It is a common site for numerous pathological processes ranging from non-neoplastic, preneoplastic to neoplastic. $^{2}$ These diseases are commonly encountered in surgical practice and are important causes of morbidity and mortality. ${ }^{3}$ GI biopsies, including endoscopic and colonoscopic biopsies and resection specimens constitute a major part in Histopathology laboratory of any tertiary referral hospital. ${ }^{4}$

GI cancers constitute a major cancer burden as colorectal cancer (CRC) ranks second, gastric cancer ranks third and esophageal cancer ranks sixth cause of cancer mortality worldwide. ${ }^{5}$ In Nepal, GI malignancies observed a rise in incidence from fifth common in 1990 to third common malignancy in 2010. Stomach cancer is the third most common cancer in males in Nepal. ${ }^{6}$

Though most commonly seen in fifth to seventh decade, rate is increasing also in younger population particularly for CRC. ${ }^{4,7}$ Most patients are aymptomatic and diagnosed at an advanced stage due to hidden location, leading to short survival time and poor prognosis..$^{8,9}$

With advent of minimally invasive fiberoptic endoscopes, visualization of different parts of GI tract has become easy. ${ }^{10}$ However, histopathological examination of biopsy remains the gold standard in diagnosing and guiding appropriate management in malignant cases. ${ }^{2,3}$

This study is conducted to see relative incidences of GI malignancies according to age, site, histopathological spectrum and seek association between differentiation and stage of cancer.

\section{METHODS}

This retrospective chart review was carried out in Department of Pathology, College of Medical Sciences and Teaching Hospital. Ethical approval from the Institutional Review Committee was obtained. 161 consecutive cases of GI malignancies found in endoscopic biopsies, colonoscopic biopsies and resection specimens received in the Histopathology section of Department of Pathology of College of Medical Sciences and Teaching Hospital during a time period of 8 years from January 2012 to December 2019 were included in the study. Malignancies of esophagus, gastresophageal (GE) junction, stomach, small intestine and large intestine were included in the study. Malignancies of oral cavity, pharynx, appendix and anal canal were excluded. Suboptimal biopsies not including submucosa and having crush artefacts were excluded. Recurrent tumors were also excluded. Malignancies were classified and staged according to World Health Organization Classification of Tumors (fourth edition). ${ }^{11}$ Histologic grading for adenocarcinoma and squamous cell carcinoma was done using protocols from College of American Pathologists. ${ }^{12-14}$ Stomach adenocarcinoma was also classified according to Lauren classification as intestinal, diffuse, 
mixed and indeterminate types. ${ }^{11}$ All the cases of GI malignancy received in the study period were reviewed from the departmental records. Data was initially entered in MS-Excel, refined and finally analyzed by SPSS 20.0. Variables like age at presentation, gender, site, size, gross type, histological type, differentiation and pathological stage at presentation were analyzed. Continuous variables were expressed as mean \pm standard deviation (SD) and categorical variables were expressed as frequencies and percentages. Association between histologic grade and pathological stage at presentation was sought using Pearson Chi square test and likelihood ratio.

\section{RESULTS}

A total of 161 cases of GI malignancies were received in the study period. Age of the patients ranged from 16 to 93 years with a mean \pm SD of $57.3 \pm 16.3$ years with maximum $36(22.4 \%)$ cases in 51-60 years followed by $35(21.7 \%)$ cases in 61-70 years age group. There were 93 (57.8\%) males and 68 (42.2\%) females with male female ratio of 1.4:1 (Table 1).

There were 60 (37.3\%) endoscopic biopsies, 20 (12.4\%) colonoscopic biopsies and 81 (50.3\%) resection specimens. $69(42.9 \%)$ cases were seen in stomach followed by 67 (41.6\%) cases in colorectum and 15 (9.3\%) cases in esophagus (Fig 1).

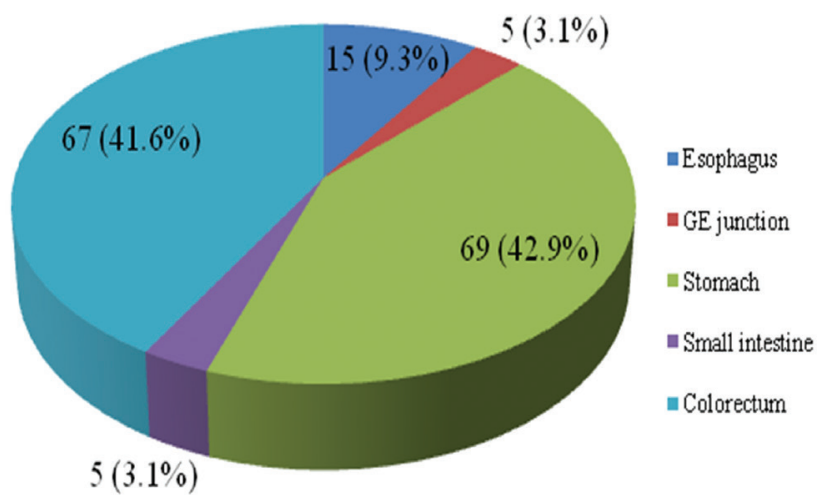

Fig 1. Pie chart showing sites of $\mathrm{GI}$ malignancies

One hundred and thirty two $(82.0 \%)$ cases of malignancies were seen after 40 years of age and only $29(18.0 \%)$ cases were seen at or below 40 years of age. However, 19 out of 67 (28.4\%) cases

Table 1. Age and gender distribution of cases $(n=161)$

\begin{tabular}{|c|c|c|c|}
\hline Age group (years) & Males $\mathbf{n}(\%)$ & Females $\mathbf{n}(\%)$ & Total $\mathbf{n}(\%)$ \\
\hline$<20$ & $2(1.2)$ & $0(0)$ & $2(1.2)$ \\
\hline $21-30$ & $5(3.1)$ & $4(2.5)$ & $9(5.6)$ \\
\hline $31-40$ & $11(6.8)$ & $7(4.3)$ & $18(11.2)$ \\
\hline $41-50$ & $14(8.7)$ & $13(8.1)$ & $27(16.8)$ \\
\hline $51-60$ & $20(12.4)$ & $16(9.9)$ & $36(22.4)$ \\
\hline $61-70$ & $17(10.6)$ & $18(11.2)$ & $35(21.7)$ \\
\hline $71-80$ & $18(11.2)$ & $7(4.3)$ & $25(15.5)$ \\
\hline$>80$ & $6(3.7)$ & $3(1.9)$ & $9(5.6)$ \\
\hline Total & $93(57.8)$ & $68(42.2)$ & $161(100)$ \\
\hline
\end{tabular}


colorectal malignancy were seen at or below 40 years of age (Table 2).
Majority, $136 \quad(84.5 \%) \quad$ cases were adenocarcinoma, followed by $10(6.2 \%)$ cases of

Table 2. Age distribution in various sites of malignancies $(n=161)$

\begin{tabular}{|c|c|c|c|c|c|c|}
\hline \multirow{2}{*}{$\begin{array}{c}\text { Age group } \\
\text { (years) }\end{array}$} & \multicolumn{5}{|c|}{ Site of malignancy } & \multirow{2}{*}{ Total } \\
\cline { 2 - 7 } & Esophagus & GE junction & Stomach & Small intestine & Colorectum & \\
\hline$<20$ & - & - & - & - & $2(1.2)$ & $2(1.2)$ \\
\hline $21-30$ & $1(0.6)$ & - & $2(1.2)$ & - & $6(3.7)$ & $9(5.6)$ \\
\hline $31-40$ & $1(0.6)$ & - & $6(3.7)$ & - & $11(6.8)$ & $18(11.2)$ \\
\hline $41-50$ & $2(1.2)$ & $1(0.6)$ & $10(6.2)$ & $2(1.2)$ & $12(12.4)$ & $27(16.8)$ \\
\hline $51-60$ & $3(1.9)$ & $1(0.6)$ & $13(8.1)$ & $2(1.2)$ & $17(10.6)$ & $36(22.4)$ \\
\hline $61-70$ & $3(1.9)$ & $1(0.6)$ & $20(12.4)$ & - & $11(6.8)$ & $35(21.7)$ \\
\hline $71-80$ & $2(1.2)$ & $2(1.2)$ & $13(8.1)$ & $1(0.6)$ & $7(4.3)$ & $25(15.5)$ \\
\hline$>80$ & $3(1.9)$ & - & $5(3.1)$ & - & $1(0.6)$ & $9(5.6)$ \\
\hline Total & $15(9.3)$ & $5(3.1)$ & $69(42.9)$ & $5(3.1)$ & $67(41.6)$ & $161(100)$ \\
\hline
\end{tabular}

Male female ratio was 1.4:1 for both stomach and colorectal malignancy, whereas it was 1.1:1 for esophageal malignancy and 1.5:1 for both GE junction and small intestine malignancy (Fig 2). squamous cell carcinoma (SCC), 6 (3.7\%) cases of Non-Hodgkin's Lymphoma (NHL) (Fig 3), 5 (3.1\%) cases of Gastrointestinal Stromal Tumor (GIST) (Fig 4), 2 (1.2\%) cases of adenosquamous

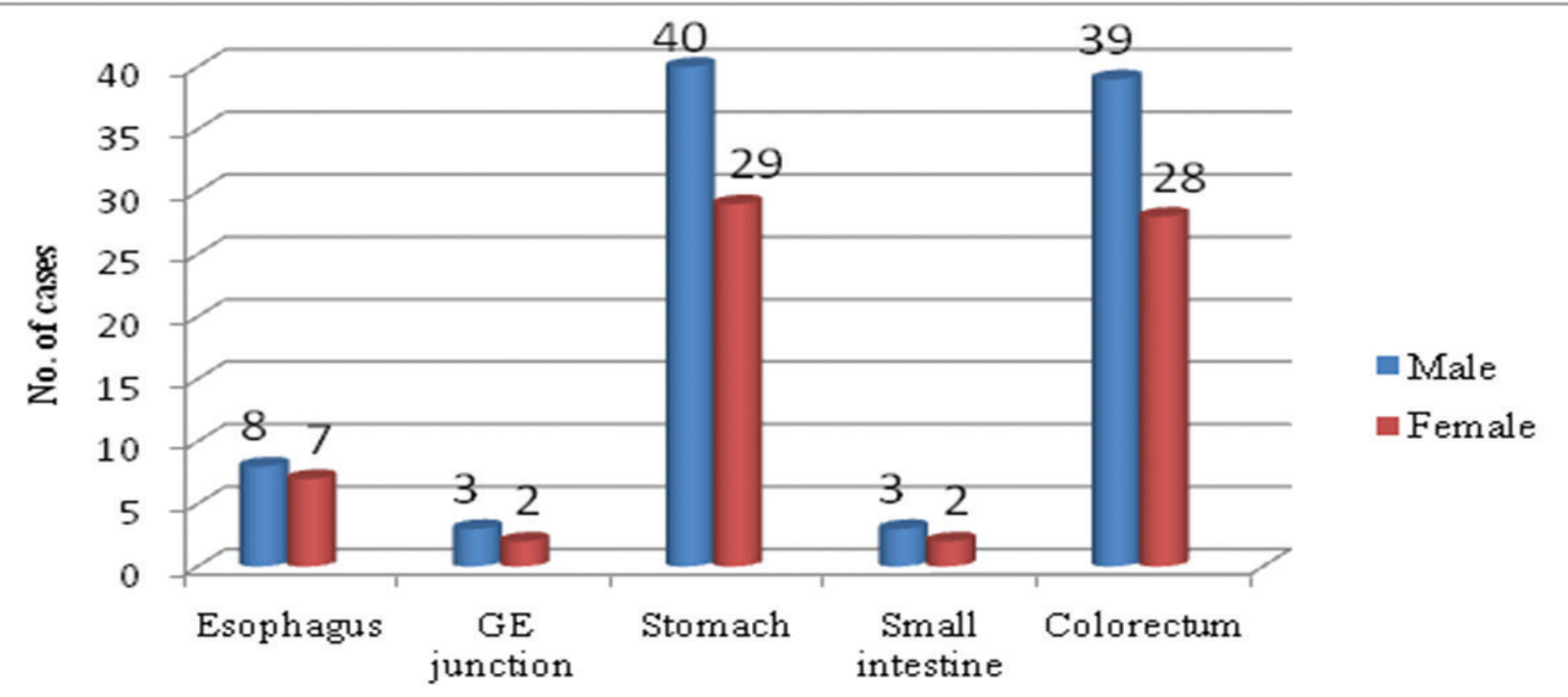

Site of malignacy

Figure 2. Bar diagram showing gender distribution in various sites of malignancies $(n=161)$ 
carcinoma and $1(0.6 \%)$ case each of small cell carcinoma and secondary metastases (Table 3).
Out of 136 cases of adenocarcinoma, 8 (5.9\%) cases were mucinous adenocarcinoma with

\begin{tabular}{|c|c|c|c|c|c|c|}
\hline \multirow[b]{2}{*}{ Histological diagnoses } & \multicolumn{5}{|c|}{ Site of malignancy } & \multirow[b]{2}{*}{ Total } \\
\hline & Esophagus & GE junction & Stomach & $\begin{array}{c}\text { Small } \\
\text { intestine }\end{array}$ & Colorectum & \\
\hline Adenocarcinoma & $3(1.9)$ & $5(3.1)$ & $64(39.8)$ & $3(1.9)$ & $61(37.9)$ & $136(84.5)$ \\
\hline SCC & $10(6.2)$ & - & - & - & - & $10(6.2)$ \\
\hline $\mathrm{NHL}$ & - & & $3(1.9)$ & - & $3(1.9)$ & $6(3.7)$ \\
\hline GIST & - & - & $2(1.2)$ & $2(1.2)$ & $1(0.6)$ & $5(3.1)$ \\
\hline $\begin{array}{l}\text { Adenosquamous } \\
\text { carcinoma }\end{array}$ & $1(0.6)$ & - & - & - & $1(0.6)$ & $2(1.2)$ \\
\hline Small cell carcinoma & $1(0.6)$ & - & - & - & - & $1(0.6)$ \\
\hline Metastases & - & - & - & - & $1(0.6)$ & $1(0.6)$ \\
\hline Total & $15(9.3)$ & $5(3.1)$ & 69 (42.9) & $5(3.1)$ & $67(41.6)$ & $161(100)$ \\
\hline
\end{tabular}

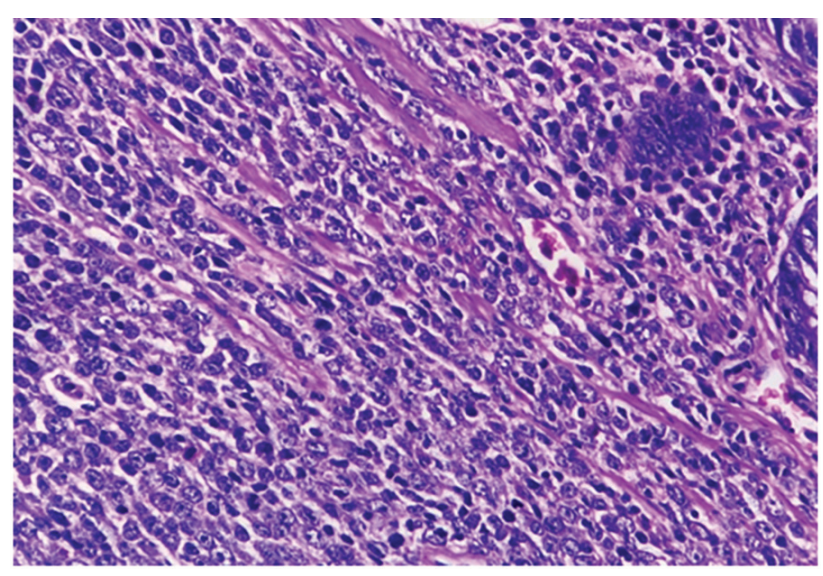

Fig 3. Diffusely infiltrating atypical lymphoid cells in NHL of colon (H and E X400)

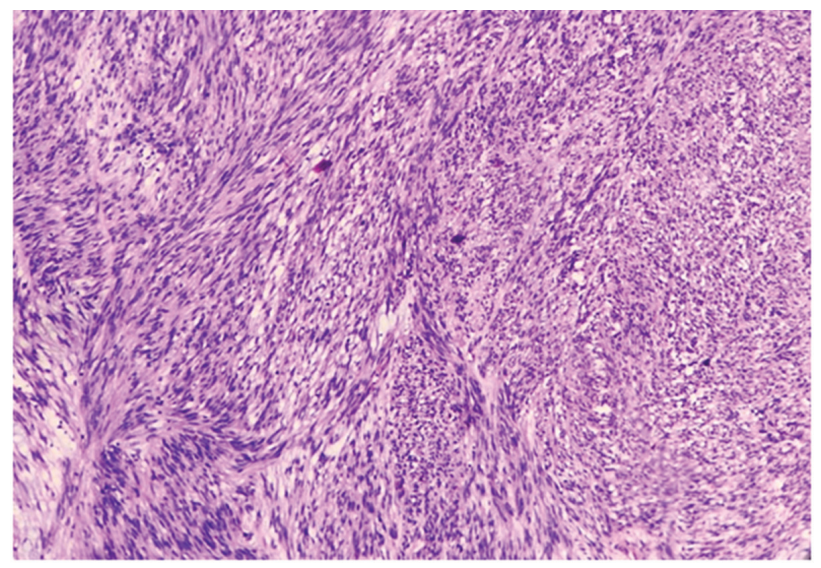

Fig 4. Intersecting fascicles of spindle cells in GIST (H and E X40)
$>50 \%$ tumor area composed of mucin (Fig 5) and $2(1.5 \%)$ cases were signet ring cell carcinoma with $>50 \%$ signet ring cells (Fig 6). 6 (10.0\%) Out of 61 adenocarcinoma in colorectum 6 (10.0\%) were mucinous adenocarcinoma whereas only $2(3.1 \%)$ cases out of 64 adenocarcinoma in stomach were mucinous adenocarcinoma. 1 case each of adenocarcinoma was signet ring cell adenocarcinoma in stomach and colorectum. 5 (62.5\%) out of 8 cases of mucinous adenocarcinoma were seen at or below 40 years of age.

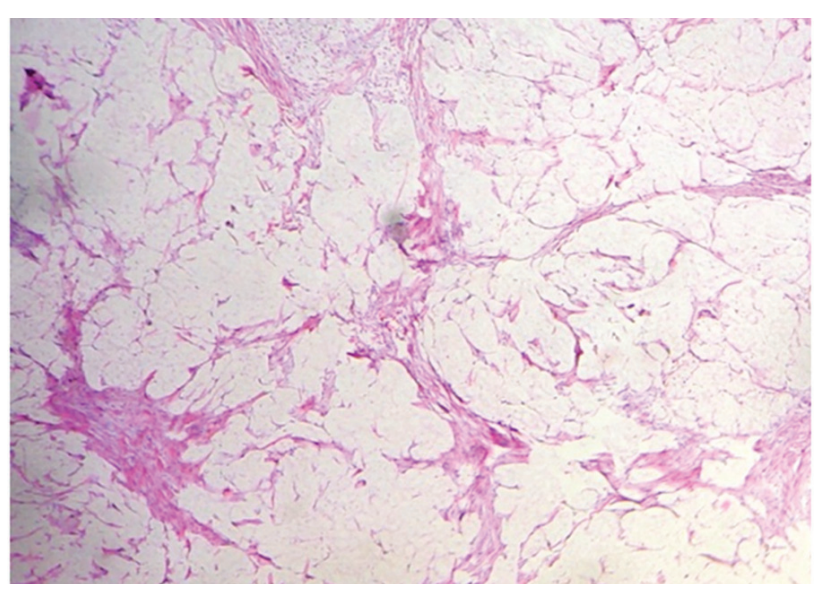

Fig 5. Tumor cells floating in pools of extracellular mucin in mucinous adenocarcinoma ( $\mathrm{H}$ and $\mathrm{E} \times 40$ ) 


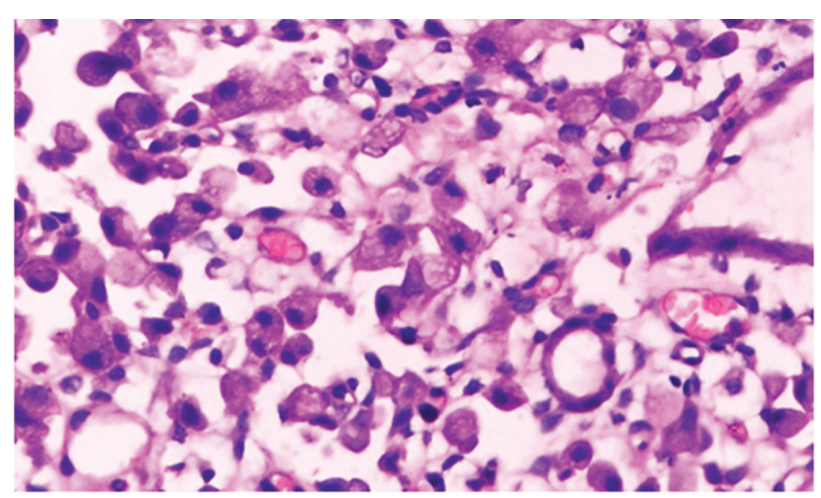

Fig 6. Signet ring cells with intracellular mucin displacing nuclei towards periphery ( $\mathrm{H}$ and $\mathrm{E} \mathrm{X400)}$

Grading was done for 146 cases of adenocarcinoma and SCC. Out of 136 cases of adenocarcinoma, 44 (32.4\%) cases were Grade 1 (Fig 7), 48 (35.3\%) cases were Grade 2 and 44 (32.4\%) cases were Grade 3 (Fig 8). Out of 10 cases of SCC, 5 (50\%) were well differentiated and 5 (50\%) were moderately differentiated (Table 4).

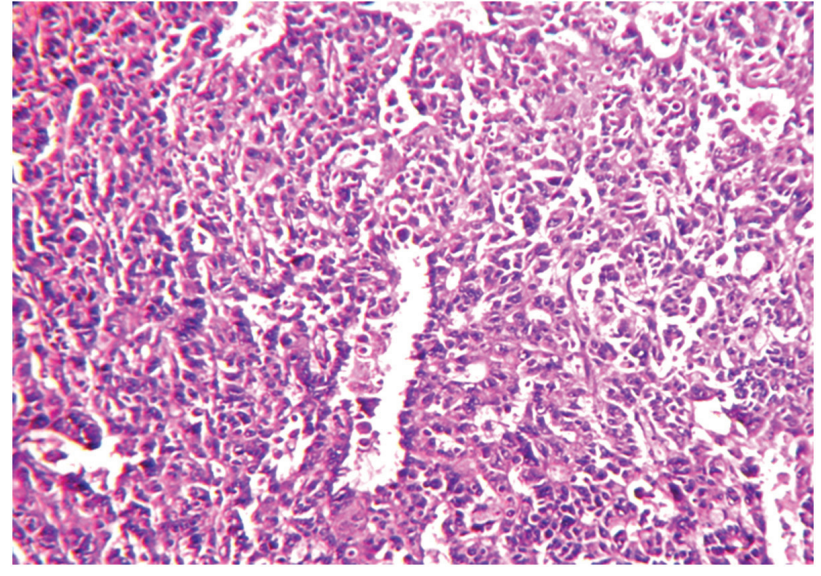

Fig 8. Poorly differentiated (Grade 3 ) adenocarcinoma with < $50 \%$ gland formation ( $\mathrm{H}$ and $\mathrm{E} \times 100$ )

According to Lauren classification, out of 64 cases of adenocarcinoma in stomach, 28 (43.8\%) cases were diffuse type (Fig 9), 26 (40.6\%) cases were intestinal type (Fig 10) and 10 (15.6\%) cases were mixed.

Table 4. Grading of adenocarcinoma and SCC in various sites $(n=146)$

\begin{tabular}{|l|l|l|l|}
\hline \multirow{2}{*}{ Site } & \multicolumn{3}{|c|}{ Histologic grade } \\
\cline { 2 - 4 } & Grade 1 & Grade 2 & Grade 3 \\
\hline \multirow{2}{*}{ Esophagus } & SCC: 5 (3.4) & SCC: 5 (3.4) & SCC: 0 \\
\cline { 2 - 4 } & Adenocarcinoma: 0 & Adenocarcinoma: 3 (2.1) & Adenocarcinoma: 0 \\
\hline GE junction & $1(0.7)$ & $2(1.4)$ & $2(1.4)$ \\
\hline Stomach & $12(8.2)$ & $22(15.1)$ & $30(20.5)$ \\
\hline Small intestine & $1(0.7)$ & $2(1.4)$ & 0 \\
\hline Colorectum & $30(20.5)$ & $19(13.0)$ & $12(8.2)$ \\
\hline Total & $49(33.6)$ & $53(36.3)$ & $44(30.1)$ \\
\hline
\end{tabular}

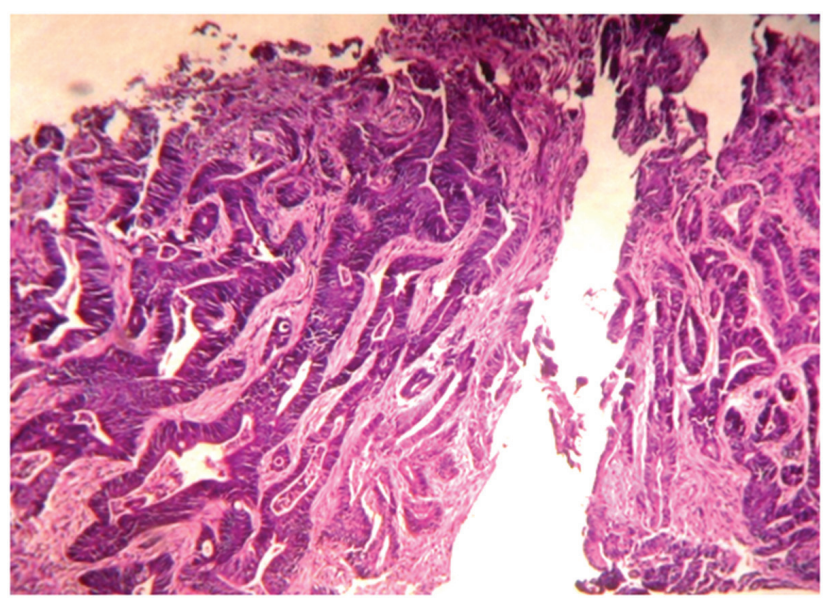

Fig 7. Well differentiated (Grade I) adenocarcinoma forming $>95 \%$ glands ( $\mathrm{H}$ and $\mathrm{E} \times 100$ )

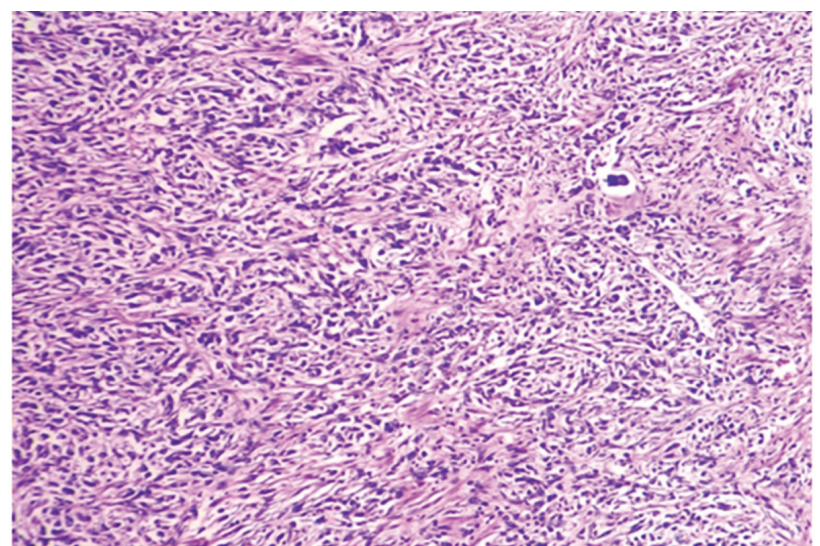

Fig 9. Diffusely infiltrating tumor cells in stomach adenocarcinoma ( $H$ and $E X 40$ ) 


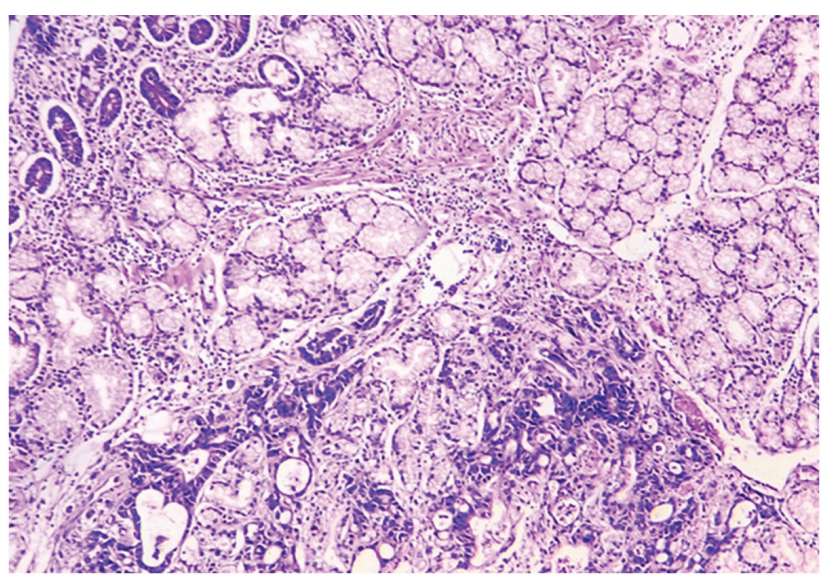

Fig 10. Tumor cells forming glands in intestinal type adenocarcinoma of stomach ( $\mathrm{H}$ and E X40) ulcerative and $6(7.4 \%)$ were fungating masses grossly. Majority $(70.0 \%)$ of the exophytic masses were seen in colorectum whereas, majority $(83.3 \%)$ of the ulcerative masses were seen in stomach and GE junction.

Pathological staging was available in 69 resected specimens. Out of these, $31(45.0 \%)$ cases were Stage III followed by 26 (37.7\%) Stage II cases (Tables 4, 5). 15 out of 31 (48.4\%) Stage III tumors were poorly differentiated (Table 5). There was no statistical significant association between histologic grade and pathologic stage at presentation as $\mathrm{p}>0.05$.

Table 5. Distribution of histologic grades in various pathologic stages of malignancies $(n=69)$

\begin{tabular}{|l|l|l|l|l|}
\hline \multirow{2}{*}{ Pathologic stage } & \multicolumn{3}{c|}{ Histologic grade } & \multirow{2}{*}{ Total } \\
\cline { 2 - 4 } & \multicolumn{1}{|c|}{ Grade I } & \multicolumn{1}{c|}{ Grade 2 } & \multicolumn{1}{c|}{ Grade 3 } & \\
\hline Stage I & $6(8.7)$ & $3(4.3)$ & $2(29.0)$ & $11(15.9)$ \\
\hline Stage II & $6(8.7)$ & $14(20.3)$ & $6(8.7)$ & $26(37.7)$ \\
\hline Stage III & $7(10.1)$ & $9(13.0)$ & $15(21.7)$ & $31(45.0)$ \\
\hline Stage IV & - & - & $1(1.4)$ & $1(1.4)$ \\
\hline Total & $19(27.5)$ & $26(37.7)$ & $24(34.8)$ & $69(100)$ \\
\hline$\chi^{2}=11.533, p=0.073$ & & & \\
\hline
\end{tabular}

Fig 10: Out of 81 resection specimens, 47 (58.0\%) cases were of colorectum, $28(34.6 \%)$ cases were of stomach, $3(3.7 \%)$ cases of GE junction, 2 $(2.5 \%)$ cases of small intestine and $1(1.2 \%)$ case of esophagus. Size of the tumors ranged from 2.0 to $15.0 \mathrm{~cm}$ with a mean \pm SD of $5.76 \pm 2.9 \mathrm{~cm}$. $34(42.0 \%)$ cases were diffusely infiltrating, $23(28.4 \%)$ were exophytic, 18 (22.2\%) were
Almost all (98.6\%) cases had infiltrated muscularis propria and beyond at presentation. Only $1(1.4 \%)$ case of stomach adenocarcinoma had infiltrated only till sumbucosa at presentation. $13.0 \%$ cases of colorectum were stage I compared to only $2.9 \%$ cases of stomach, which were Stage I (Table 6).

Table 6. Distribution of site in various pathologic stages of malignacies ( $n=69$ )

\begin{tabular}{|c|c|c|c|c|c|c|}
\hline Pathological stage & \multicolumn{7}{|c|}{ Site of malignancy } & \multirow{2}{*}{ Total } \\
\cline { 1 - 7 } & Esophagus & GE junction & Stomach & Small intestine & Colorectum & \\
\hline Stage I & - & - & $2(2.9)$ & - & $9(13.0)$ & $11(15.9)$ \\
\hline Stage II & $1(1.4)$ & $1(1.4)$ & $8(11.6)$ & - & $16(23.2)$ & $26(37.7)$ \\
\hline Stage III & - & $2(2.9)$ & $13(18.8)$ & - & $16(23.2)$ & $31(45.0)$ \\
\hline Stage IV & - & - & - & - & $1(1.4)$ & $1(1.4)$ \\
\hline Total & $1(1.4)$ & $3(4.3)$ & $23(33.3)$ & 0 & $42(60.9)$ & $69(100)$ \\
\hline
\end{tabular}




\section{DISCUSSION}

Parts of GI tract comprise top ten leading sites for cancer worldwide. ${ }^{15}$ Remarkable differences are noted in occurrence of these malignancies in different parts of world and different races. ${ }^{9}$ Most cases are diagnosed at an advanced stage due to non-specific symptoms and hidden location. ${ }^{9}$ In Nepal also, GI malignancies are a major health challenge, as most cases present at advanced stage. Many of the causes of delay in diagnosis and treatment are preventable. ${ }^{16}$ Endoscopic examination followed by biopsy is currently the major method of diagnosing GI neoplasms. ${ }^{2}$ Histopathological evaluation is the gold standard for early detection of GI malignancies. ${ }^{17}$

Present study was carried on 161 cases of GI malignancies. Age of the patients ranged from 16 to 93 years with a mean \pm SD of $57.3 \pm 16.3$ years and maximum $36(22.4 \%)$ cases were seen in 51 - 60 years age group. In study conducted by Thakur et al, age of the patients ranged from 29 to 104 years with a mean of 58.7 years and maximum $34.6 \%$ cases in 50 - 60 years age group which was similar to our study. ${ }^{17}$ In a study conducted in Nepal, median age at diagnosis was 52.5 years. ${ }^{16} 44.1 \%$ cases were seen between $5^{\text {th }}$ to $7^{\text {th }}$ decade in present study, whereas Ekta et al observed a higher $68.6 \%$ cases and BazazMalik et al observed a much higher $83.3 \%$ in the same age group suggesting more incidence in elder age group. ${ }^{4} 18$ Present study observed 29 $(18.0 \%)$ cases at or below 40 years of age. Thakur et al also observed $18.9 \%$ cases at or below 40 years of age. ${ }^{17}$ Recent epidemiological studies indicate that rate of GI malignancies is increasing in young adults, particularly colorectal cancer. ${ }^{7}$ Male to female ratio was 1.4:1 which was similar to finding of Ekta et al, where male to female ratio was 1.33:1 in malignant cases. ${ }^{4}$ Thakur et al had observed a much higher 1.7:1 male female ratio. $^{17}$

Most common site was stomach in $42.9 \%$ followed by colorectum in $41.6 \%$ cases. Trisal et al had observed almost equal involvement of stomach and large intestine comprising 26.7\% cases each which was comparable to our study. ${ }^{2}$ In a 25 years study conducted by Bazaz-Malik et al, large intestine was the most common site involved in $43.3 \%$ cases and stomach was involved in $11.3 \%$ cases. The authors had also included oropharyngeal cancers which were second most common. ${ }^{18}$ Thakur et al had observed a much higher $66 \%$ cases in colorectum and only $7.5 \%$ cases in stomach. ${ }^{17}$ Ekta et al had found $45.7 \%$ cases in colorectum and anal canal and only $5.7 \%$ cases in stomach. ${ }^{4}$ In one study from Nepal, colorectal malignancy comprised $48 \%$ and gastroesophageal malignancy combined comprised 58\%. ${ }^{16}$ Gastric cancer is the most common GI malignancy in Nepal. ${ }^{19}$ Present study also observed most common site as stomach.

Adenocarcinomais the mostcommon histological type of cancer occurring in GI tract except for esophagus, where SCC is most common in high risk areas. ${ }^{1,11}$ Extra-nodal lymphomas arise most commonly in GI tract, particularly in stomach. ${ }^{1}$ Present study observed equal incidence of NHL in stomach and large intestine. GIST cases are more common in stomach in GI tract. ${ }^{1}$ However, in present study 2 cases each were equally seen in small intestine and stomach. Sample size of both NHL and GIST were less in our study. More number of cases can provide better results.

Majority (46.9\%) cases stomach adenocarcinoma were poorly differentiated as compared to majority $(49.2 \%)$ cases of colorectal adenocarcinoma which were well differentiated. In study conducted by Moghimi-Dehkordi et al also, majority of gastric cancer were poorly 
differentiated (46.2\%) and majority of CRC were well differentiated $(55.5 \%)$ similar to present study. ${ }^{20}$ Histologic grade also provides prognostic information in addition to stage of disease. Poorly differentiated tumors pursue a more aggressive course. Difference in survival between low grade and high grade tumors was more pronounced for adenocarcinoma than SCC of esophagus. For stomach, difference in survival between low grade and high grade tumor was seen more when cancer was localized and survival was independent of histologic grade in the metastatic disease. For CRC, in all the stages survival was also dependent on grade of tumor, more pronounced for stage with regional spread. ${ }^{21}$ For CRC, survival is significantly related to histologic grade and presence of distant metastases, however for gastric cancer, survival is related to presence of distant metastases only. ${ }^{20}$ Present study did not observe any association between histologic grade and pathologic stage of malignancy at presentation.

$46.4 \%$ cases were found in stage III/IV in present study as compared to $84 \%$ found by Dulal et al. ${ }^{16}$ This study observed more cases in earlier stage. Staging done was pathologic and was dependent entirely on nature of specimen sent, which may not have provided true insight into the distant metastases. Various GI symptoms are frequent in Nepal and these symptoms are interpreted more often of non-cancerous origin. Over the counter medicines are also easily available in Nepal leading to delay of patients in seeking medical help. This delay and poor awareness in population needs to be addressed.22

\section{Esopahgus}

Esophagus was involved in 15 (9.3\%) cases. Various studies have shown a higher proportion ranging from $16.7 \%$ to $37.1 \%$ cases of esophageal malignancy out of total GI malignancies. 2, 4, 17, 23 Bazaz-Malik et al have shown lower 6.5\% involvement of esophagus. ${ }^{18}$ Age of the patients ranged from 23 to 87 years of age and $73.3 \%$ cases were seen after 50 years of age. In study conducted by McHembe et al, age ranged from 24 to 78 years and $51.8 \%$ cases were seen after 50 years of age. ${ }^{23}$ Male female ratio for esophageal malignancy was found to be 1.1:1. McHembe et al reported 2.2:1 male female ratio which is much higher than present study. ${ }^{23}$ Males are 2 - 10 times more affected than females. ${ }^{11}$ Present study did not observe so. This may be because of less number of cases. $10(66.7 \%)$ cases were SCC, $3(20.0 \%)$ cases were adenocarcinoma and $1(6.7 \%)$ case each was adenosquamous carcinoma and small cell carcinoma. McHembe et al had reported 96\% SCC and $4 \%$ adenocarcinoma. ${ }^{23}$ Hirachand et al had reported all esophageal malignancies as SCC. ${ }^{3}$ Incidence of adenocarcinoma of esophagus is increasing. ${ }^{11,24}$ Adeoncarcinoma and SCC differ clinically, histologically and oncologically with different therapeutic concept. ${ }^{24}$ Adenosquamous carcinoma is uncommon in esophagus having distinct squamous and glandular components. They have a better prognosis than conventional squamous cell carcinoma or adenocarcinoma. ${ }^{25}$ Small cell carcinoma of esophagus is a rare disease with rapid progression and incidence ranges from $0.8-2.4 \%{ }^{26}$

\section{GE junction}

5(3.1\%) cases wereseenin GEjunction.Ageranged from 46 to 80 years and $80 \%$ cases were seen after 50 years. All cases were adenocarcinoma. Trisal et al had reported 10\% cases in GE junction and all cases as adenocarcinoma.2Adeoncarcinoma of GE junction is defined as cancer with epicenter located within $5 \mathrm{~cm}$ of GE junction and extending into esophagus.27Incidence of adenocarcinoma of GE junction has been increasing in Western 
countries due to higher prevalence of obesity and gastroesophageal reflux. ${ }^{28}$

\section{Stomach}

Stomach was the most common site involved in $42.9 \%$ cases in present study. Incidence of gastric cancer is highest in Eastern Asia, Eastern Europe and South America and lower in Western Europe and North America. ${ }^{29}$ Age of the patients ranged from 25 to 93 years and $74.0 \%$ cases were seen after 50 years of age. Male female ratio was 1.4:1. According to Prasad et al. age ranged from 23 to 98 years with maximum 71.3\% cases in fifth to seventh decade which was similar to our study. ${ }^{30}$ However, Ali et al, had observed peak at comparatively younger age with a mean of 43.1 years. ${ }^{31}$ Both Prasad et al and Ali et al had observed a higher male female ratio of 2:1 and 2.4:1 respectively which were higher than present study. ${ }^{30,31}$ Ulcerative morphology was most common comprising $43.0 \%$ cases which was similar to finding of Prasad et al. ${ }^{30} 92.8 \%$ cases were adenocarcinoma and $4.3 \%$ and $2.9 \%$ cases were NHL and GIST respectively. Prasad et al had observed $97.5 \%$ cases of adenocarcinoma, $1.3 \%$ cases of carcinoid, $0.7 \%$ cases each of GIST and NHL respectively. ${ }^{30}$ Ali et al had observed $98.3 \%$ cases of adenocarcinoma and $1.7 \%$ cases of NHL. ${ }^{31} 43.8 \%$ cases were diffuse type, $40.6 \%$ cases were intestinal type and $15.6 \%$ cases were mixed. In a study conducted by Talukder et al, intestinal type were most common comprising of $68.9 \%$, diffuse type were $14.3 \%$ and rest were mixed type. ${ }^{32}$ In a study conducted by MartinezGalindo et al, diffuse type was more common comprising $55.2 \%$ followed by $28.2 \%$ intestinal type. Diffuse type was significantly found more in younger individuals. ${ }^{33}$ Though the incidence rates for gastric cancer are decreasing, these rates are decreasing for intestinal type, rate of diffuse type localized to proximal stomach has been increasing. Diffuse type has a worse outcome as compared to intestinal type. ${ }^{1,11}$ Majority (46.9\%) of adenocarcinoma were poorly differentiated which was similar to finding of Ali et al where $57.1 \%$ were poorly differentiated..$^{31}$

\section{Small intestine}

Small intestine comprised only 5 (3.1\%) cases. $3(60 \%)$ cases were adenocarcinoma and 2 (40.0\%) cases were GIST. Small intestine though accounts for $75 \%$ overall length of GI tract, is an uncommon site for both benign and malignant tumors. ${ }^{1}$ Adenocarcinoma of small intestine are rare. ${ }^{11}$ Thakur et al had observed only case of malignancy in small intestine in their study. ${ }^{17}$ Bazaz-Malik had observed $4.4 \%$ cases in small intestine. $^{18}$

\section{Large intestine}

Large intestine was involved in 67 (41.6\%) cases. Age ranged from 16 - 88 years with mean 51.9 years and maximum $43.3 \%$ cases in $4^{\text {th }}$ to $6^{\text {th }}$ decade. Male female ratio was 1.4:1. Various studies conducted in Nepal have reported age range of $18-87$ years, mean age of 52,53 and 57.3 years and male female ratio of 0.9:1, 1.03:1 and $1.3: 1 .^{22,34,35} 28.4 \%$ cases were seen at or below 40 years of age in present study. In study conducted by Shah et al and Kansakar et al 16.7\% and 28\% cases respectively were seen below 40 years of age. ${ }^{34,36}$ In studies conducted by Rajbhandari et al and Rawal et al, 36\% and 37\% patients were less than 50 years of age respectively. ${ }^{22,37} \mathrm{CRC}$ in young adults is more frequently reported from developing countries and is in increasing trend. The patients in this age group are of better physical condition and due to lack of awareness tend to ignore symptoms. Aggressive tumor biology and delay in diagnosis often cause these patients to land in advanced stage. ${ }^{36,37} 91.0 \%$ cases were adenocarcinoma and majority of them (49.2\%) were well differentiated. Studies conducted in Nepal have also shown adenocarcinoma to 
be most common but moderately and poorly differentiated tumors were reported more commonly. ${ }^{34,36,37}$ However, Ibrahim et al had reported $52.3 \%$ cases as well differentiated in their study which was in accordance with present study. ${ }^{38}$ Poorly differentiated tumors proliferate and metastasize more than well differentiated..$^{39}$ Out of 8 cases of mucinous adenocarcinoma seen in present study $75 \%$ were seen in colorectum. All cases were seen below 50 years of age. Mucinous adenocarcinoma is a distinct subtype characterized by the presence of abundant extracellular mucin which accounts for at least $50 \%$ of the tumor volume. Mucinous colorectal adenocarcinoma is found in 10\%-20\% of CRC patients and occurs more commonly in younger patients. This histology is an adverse prognostic indicator. ${ }^{40} 21.4 \%$ cases were Stage I followed by $38.1 \%$ cases each of Stage II and Stage III and $2.4 \%$ cases were stage IV. Rawal et al had reported a higher $35.8 \%$ cases in Stage I followed by $31.6 \%$ cases in Stage III. ${ }^{37} 5$ year survival for CRC is $90 \%$ for patients with localized disease, 69\% for regional spread and below $12 \%$ for distant metastasis. ${ }^{41}$ Stage I and II tumors are localized, Stage III tumors show regional lymph node involvement and Stage IV tumors show distant metastasis. ${ }^{14}$ 59.5\% cases of CRC in this study presented in Stage I and II implying better prognosis.

\section{CONCLUSION}

GI malignancy constitutes a significant cancer burden. Though it affects mostly elderly individuals, younger individuals are also considerably affected denoting a need of high degree of suspicion even in younger patients presenting with GI symptoms. Stomach was the most common site involved. Adenocarcinoma was the most common histological type. There was no association between histologic grade and pathologic stage at presentation.

\section{ACKNOWLEDGEMENTS}

We would like to thank Department of GI Surgery for sending us cases.

\section{Conflicts of interest}

None declared.

\section{REFERENCES}

1. Turner JR. The gastrointestinal tract. In: Kumar V, Fausto N, Aster JC, Abbas AK. Robbibs and Cotran Pathologic basis of disease. 8th ed. Philadelphia: Elsevier; 2010. p.763-832.

2. Trisal M, Goswami KC, Khajuria A. A Study of Histopathological Spectrum of Gastrointestinal Endoscopic Biopsies in a Tertiary Care Centre. Saudi Journal of Pathology and Microbiology. 2018;3(8):226-34. DOI: 10.21276/ sjpm.2018.3.8.3

3. Hirachand S, Sthapit RR, Gurung P,

Pradhanang S, Thapa R, Sedhai M et al. Histopathological spectrum of upper gastrointestinal endoscopic biopsies. Journal of BP Koirala Institute of Health Sciences. 2018;1(1):67-8. DOI: 10.3126/ jbpkihs.v1i1.19760

4. Ekta, Bansal N, Roychoudhary AK, Shaffy. A Histopathological Spectrum of Gastrointestinal Tract Lesions in a Tertiary Care Centre in South Western Part of India: An Epidemiological Study. Journal of Krishna Institute of Medical Sciences University. 2018;7(3):43-7. 
5. Bray F, Ferlay J, Soerjomataram I, Siegel RL, Torre LA, Jemal A. Global cancer statistics 2018: GLOBOCAN estimates of incidence and mortality worldwide for 36 cancers in 185 countries. CA: a cancer journal for clinicians. 2018;68(6):394424. DOI: $10.3322 /$ caac. 21492

6. Piya MK, Acharya SC. Oncology in Nepal. South Asian journal of cancer. 2012;1(1):5-8. doi: 10.4103/2278330X.96490

7. Perl G, Nordheimer S, Lando S, Benedict C, Brenner B, Perry $S$, et al. Young patients and gastrointestinal (GI) tract malignancies - are we addressing the unmet needs? BMC cancer. 2016;16:630. doi: 10.1186/s12885-016-2676-4

8. Cao W, Zhang CL. Enteral immunonutrition for malignant gastrointestinal tumor during perioperative period: a metaanalysis. Chinese Journal of EvidenceBased Medicine 2013; 13(8): 992-1000.

9. Mohandas KM. Tumours of the gastrointestinal tract. In: Shaha SN. API textbook of Medicine 8th ed. Mumbai: The Association of Physicians of India;2008.p.881.

10. Kasturi S, Mulaka R. ClinicoPathological Study of Endoscopic Gastric Biopsies. Journal of Chalmeda Anand Rao Institute of Medical Sciences. 2018;15(1):112-16.

11. Bosman FT, Carneiro F, Hruban RH, Theise ND. WHO Classification of Tumors of the Digestive System. 4 th ed. Lyon: IARC; 2010.

12. Protocol for the Examination of Specimens From Patients With
Carcinoma of the Esophagus [Internet]. [Place unknown]: College of American Pathologists; 2017 [cited 2020 July 22]. Available from: http://www. documents.cap.org/protocols/cpesophagus-17protocol-4000.pdf

13. Protocol for the Examination of Specimens From Patients With Carcinoma of the Stomach [Internet]. [Place unknown]: College of American Pathologists; 2017 [cited 2020 July 22]. Available from: http://www. documents.cap.org/protocols/cpstomach-17protocol-4000.pdf

14. Protocol for the Examination of Specimens From Patients With Carcinoma of the Colon and Rectum [Internet]. [Place unknown]: College of American Pathologists; 2017 [cited 2020 July 22]. Available from: http://www. documents.cap.org/protocols/capcolon-rectum-2017-v4000.pdf

15. Stewart BW, Kleihues P. World Health Organisation. World Cancer Report. Lyon: IARC Press, 2003.

16. Dulal S, Paudel BD, Shah A, Acharya B, Acharya SC, Thapa RR, et al. Delay in diagnosis and treatment of gastrointestinal cancer in Nepal. Journal of Clinical Oncology. 2019;37(15_ suppl):e18269-e. doi/abs/10.1200/ JCO.2019.37.15_suppl.e18269

17. Thakur RY, Nikumbh DB, Swami SY. Clinico Histopathological Overview of GIT Lesions in a Rural Hospital. Indian Journal of Pathology and Oncology. 2016;3(2):305-14.DOI: $\quad$ 10.5958/23946792.2016.00058.2

18. Bazaz-Malik G, Lal N. Malignant tumours of the digestive tract. A 
twenty five year study. Indian Journal of Pathology and Microbiology. 1989;32(3):179-85.

19. Kandel B, Kansakar P, Singh Y. Gastric cancer in young adults: Experience from Nepal. Annals of Oncology. 2014;25:ii29.

20. Moghimi-Dehkordi B, Safaee A, Zali MR. Comparison of colorectal and gastric cancer: survival and prognostic factors. Saudi J Gastroenterol. 2009;15(1):18-23. doi: 10.4103/13193767.43284

21. Marisa T. Carriaga DEH. The histologic grading of cancer. Cancer 1995;75(S1):406-21. DOI: 10.1002/10970142(19950101)75: $\quad 1+<406$ ::aidcncr2820751322>3.0.co;2-w

22. Rajbhandari M, Karmacharya A, Khanal K, Dhakal P, Shrestha R. Histomorphological Profile of Colonoscopic Biopsies and Pattern of Colorectal Carcinoma in Kavre District. Kathmandu University medical journal (KUMJ). 2015;11:196200. DOI: 10.3126/kumj.v11i3.12503

23. McHembe MD, Rambau PF, Chalya PL, Jaka H, Koy M, Mahalu W. Endoscopic and clinicopathological patterns of esophageal cancer in Tanzania: experiences from two tertiary health institutions. World J Surg Oncol. 2013;11:257. doi: 10.1186/1477-7819-11257

24. Mariette C, Finzi L, Piessen G, Van Seuningen I, Triboulet JP. Esophageal carcinoma: prognostic differences between squamous cell carcinoma and adenocarcinoma. World Journal of
Surgery. 2005;29(1):39-45. DOI: 10.1007/ s00268-004-7542-x

25. Yachida S, Nakanishi $Y$, Shimoda T, Nimura S, Igaki H, Tachimori $Y$, et al. Adenosquamous carcinoma of the esophagus. Clinicopathologic study of 18 cases. Oncology. 2004;66(3):218-25. DOI: $10.1159 / 000077998$

26. Shimoda T, Koizumi W, Tanabe S, Higuchi K, Sasaki T, Nakayama N, et al. Small-Cell Carcinoma of the Esophagus Associated with a Paraneoplastic Neurological Syndrome: A Case Report Documenting a Complete Response. Japanese Journal of Clinical Oncology. 2006;36(2):109-12. https:// doi.org/10.1093/jjco/hyi241

27. Szanto I, Voros A, Gonda G, Nagy P, Altorjay A, Banai J, et al. [Siewert-Stein classification of adenocarcinoma of the esophagogastric junction]. Magyar sebeszet. 2001;54(3):144-9.

28. Wu A, Ji J. Adenocarcinoma of esophagogastric junction requires a clearer definition. Translational Gastrointestinal Cancer. 2013;2(suppl 1):5-9. doi: 10.3978/j.issn.22244778.2013.05.41

29. Smyth EC, Verheij M, Allum W, Cunningham D, Cervantes A, Arnold D, et al. Gastric cancer: ESMO Clinical Practice Guidelines for diagnosis, treatment and follow-up. Annals of Oncology. 2016;27(suppl 5):v38-v49. DOI: 10.1093/annonc/mdt344

30. Prasad S, Ravindra S, Venkat G, B V S. Gastric neoplasms - An endoscopic biopsy study with review of literature. International Journal of Biomedical 
Research. 2013;4:704. DOI:10.7439/ijbr

31. Ali S, Ahmed S, Afroz Q, Chowdhury R, Huda M. Histopathologic Pattern of Gastric Cancer in Bangladesh. Journal of Armed Forces Medical College, Bangladesh. 2009;5(1):21-4. DOI: 10.3329/jafmc.v5i1.2846

32. Wachtel MS, Zhang Y, Chiriva-Internati M, Frezza EE. Different regression equations relate age to the incidence of Lauren types 1 and 2 stomach cancer in the SEER database: these equations are unaffected by sex or race. BMC cancer. 2006;6(1):65. doi: 10.1186/1471-2407-665

33. Martinez-Galindo MG, ZamarripaDorsey F, Carmona-Castaneda A, Angeles-Labra A, PenaveraHernandez R, Ugarte-Briones C, et al. Histopathologic characteristics of gastric adenocarcinoma in Mexican patients: a 10-year experience at the Hospital Juarez of Mexico. Revista de gastroenterologia de Mexico. 2015;80(1):21-6. DOI: 10.1016/j. rgmx.2014.11.002

34. Shah S, Shrestha S, Shah JN, Paudyal S. Clinico-pathological characteristics of colorectal carcinoma at university teaching hospital, Nepal. Journal of Patan Academy of Health Sciences. 2014;1(2):35-8. DOI: 10.3126/jpahs. v1i2.16644

35. Ghimire B, Kurlberg G, Singh YP, Wettergren Y. Comparison of Nepalese and Swedish Patients with Colorectal Cancer Regarding Tumor Suppressor
Methylation in Tumor and Mucosa Samples. Journal of Institute of Medicine Nepal. 2020;42(1):73.

36. Kansakar P, Singh Y. Changing Trends of Colorectal Carcinoma in Nepalese Young Adults. Asian Pacific journal of cancer prevention : APJCP. 2012;13(7):3209-12. DOI: 10.7314/ APJCP.2012.13.7.3209

37. Rawal S, Thapa A, Jha MK, Laudari U. Colorectal Cancer in Young Age Group: Where do we stand? 2019;21(2):104-9. DOI: $10.3126 /$ nmcj.v21i2.25108

38. Ibrahim K, Anjorin A, Afolayan A, Badmos K. Morphology of colorectal carcinoma among Nigerians: A 30-year review. Nigerian Journal of Clinical Practice. 2011;14(4):432-5.

39. Takeuchi K, Kuwano H, Tsuzuki Y, Ando T, Sekihara M, Hara T, et al. Clinicopathological characteristics of poorly differentiated adenocarcinoma of the colon and rectum. Hepatogastroenterology. 2004;51(60):1698702.

40. Luo C, Cen S, Ding G, Wu W. Mucinous colorectal adenocarcinoma: clinical pathology and treatment options. Cancer communications. 2019;39(1):13. doi: 10.1186/s40880-019-0361-0

41. Siegel R, DeSantis C, Virgo K, Stein K, Mariotto A, Smith T, et al. Cancer treatment and survivorship statistics, 2012. CA: a cancer journal for clinicians. 2012;62(4):220-41. DOI: 10.3322/ caac. 21149

Citation: Goyal G, Sedhain M, Subedi P, Rai S. Gastrointestinal Malignancies: An Eight Years Experience. JCMS Nepal. $2021 ; 17(2) ; 145-58$. 